\title{
Observation of Dislocation Dynamics in the Electron Microscope
}

B. W. Lagow, I. M. Robertson, M. Jouiad, D. H. Lassila, T. C. Lee, H. K. Birnbaum

\section{August 21, 2001}

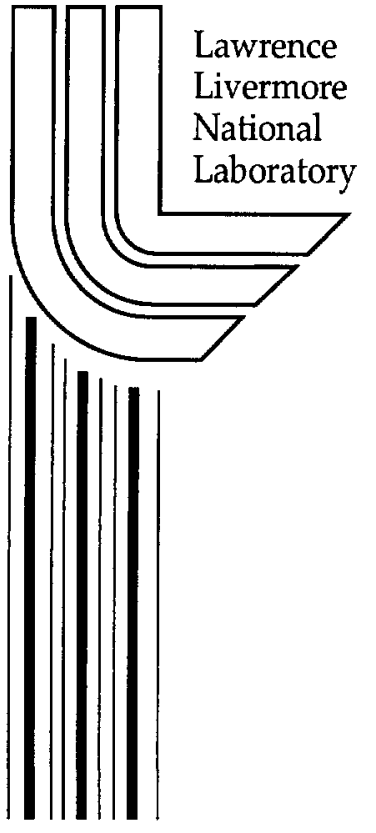




\section{DISCLAIMER}

This document was prepared as an account of work sponsored by an agency of the United States Government. Neither the United States Government nor the University of California nor any of their employees, makes any warranty, express or implied, or assumes any legal liability or responsibility for the accuracy, completeness, or usefulness of any information, apparatus, product, or process disclosed, or represents that its use would not infringe privately owned rights. Reference herein to any specific commercial product, process, or service by trade name, trademark, manufacturer, or otherwise, does not necessarily constitute or imply its endorsement, recommendation, or favoring by the United States Government or the University of California. The views and opinions of authors expressed herein do not necessarily state or reflect those of the United States Government or the University of California, and shall not be used for advertising or product endorsement purposes.

This work was performed under the auspices of the U. S. Department of Energy by the University of California, Lawrence Livermore National Laboratory under Contract No. W-7405-Eng-48.

This report has been reproduced directly from the best available copy.

Available electronically at http://www.doc.gov/bridge

Available for a processing fee to U.S. Department of Energy

And its contractors in paper from

U.S. Department of Energy

Office of Scientific and Technical Information

P.O. Box 62

Oak Ridge, TN 37831-0062

Telephone: (865) 576-8401

Facsimile: (865) 576-5728

E-mail: reports@adonis.osti.gov

Available for the sale to the public from

U.S. Department of Commerce

National Technical Information Service

5285 Port Royal Road

Springfield, VA 22161

Telephone: (800) 553-6847

Facsimile: (703) 605-6900

E-mail: orders@ntis.fedworld.gov

Online ordering: http://www.ntis.gov/ordering.htm

\section{OR}

Lawrence Livermore National Laboratory

Technical Information Department's Digital Library

http://www.llnl.gov/tid/Library.html 


\title{
OBSERVATION OF DISLOCATION DYNAMICS IN THE ELECTRON MICROSCOPE
}

B. W. Lagow*, I. M. Robertson*, M. Jouiad*. D. II. Lassilat, T. C. Lee*, and H. K. Birnbaum*

* Frederick Scitz Matcrials Research Laboratory, University of Illinois at Urbana-Champaign, Urbana IL 61801

Materials Science and Technology Division, Lawrence Livermore National Laboratory, Livermore CA 94550

\begin{abstract}
Deformation experiments performed in-situ in the transmission electron microscope have led to an increased understanding of dislocation dynamics. To illustrate the capability of this technique two examples will be presented. In the first example, the processes of work hardening in Mo at room temperature will be presented. These studies have improved our understanding of dislocation mobility, dislocation generation, and dislocation-obstacle interactions. In the second example, the interaction of matrix dislocations with grain boundaries will be described. From such studies predictive criteria for slip transfer through grain boundaries have been developed.
\end{abstract}

\section{INTRODUCTION}

By performing dynamic experiments in-situ in a transmission electron microscope, it is possible to directly observe changes in microstructure caused by external stimuli. In-situ straining of materials is a particularly useful and illustrative example, as it provides the means to observe dislocation interactions and microstructure evolution dynamically. It is, however, important to be cognizant of the sample thickness, and of the influence the nearby surface can have on dislocation behavior. 
Provided the observations are analyzed cautiously and comparisons are made with other techniques, in-situ deformation can provide useful insight to dislocation behavior. Such observations are particularly important to current efforts in multiscale modeling of deformation of materials, as they provide a means for testing the code output. The in-situ TEM deformation experiments also underscore the complex issues that must be addressed by a successful simulation.

In this paper, we present two examples of experimental results that would not have been possible without the in-situ TEM deformation technique. In the first, we discuss dislocation generation and work hardening in high-purity, single-crystal Mo, and in the second, slip transfer across grain boundaries.

\section{EXPERIMENTAL PROCEDURE}

The TEM straining samples typically have dimensions of $3 \mathrm{~mm} \times 10 \mathrm{~mm}$ and are between 100 and $200 \mu \mathrm{m}$ thick. The central portion of the rectangular specimen is thinned to electron transparency by conventional methods. In-situ straining was performed using a single-tilt straining stage and dynamic events were recorded through a TV-rate camera onto videotape. The single-tilt straining stage is designed so that one end of the sample remains fixed, while the other end is displaced.

\section{RESULTS}

Deformation in high-purity, single-crystal Mo 
The Mo samples used in this investigation were zone-refined single crystals, UHV annealed at $850^{\circ}$ C for $24 \mathrm{~h}$. Samples from one crystal contained a high dislocation density [1]. The dislocations were either isolated or arranged in tangles that were composed of intersecting $a / 2\langle 111\rangle$ perfect dislocations, with short a $<100>$ junction dislocations forming at the intersections. These dislocation tangles were important as they acted as dislocation sources and as obstacles to mobile dislocations. In the initial stages of deformation, edge dislocation segments propagated from the tangles and trailed behind them long, straight serew dislocations, which are immobile at room temperature and at low stress [2]; see Figure 1 for an example. At higher stresses, the screw dislocations become mobile and initially moved smoothly on one slip plane. As the density of mobile dislocations increased and more interactions occurred, the dislocations cross-slipped to negotiate the obstacles. An example of cross-slip is shown in Figure 2 in which comparison images formed by superimposing a negative image (white dislocations) of a later frame on a positive image of an earlier frame are shown. The change in dislocation position as a function of time is apparent and corresponds to screw dislocations cross-slipping between $\{110\}$ and $\{112\}$ planes.

The series of video images presented in Figure 3 show two methods used by screw dislocations to overcome an obstacle; in these images the obstacles are not visible. Cusps are observed on the dislocations where they interact with a strong obstacle. The unpinned segments on dislocation 1 continue to slip past the obstacle and eventually the dipole is pinched off, allowing the screw dislocation to continue its motion. Dislocation 2 negotiates its obstacle differently, requiring crossslip of a segment of the dislocation at the obstacle. As the line segment on the left of the cusp in 2 continues to slip, its edge component expands to produce the loop seen at $t=7 \mathrm{~s}$. The segments pinch off and the screw dislocation again moves as a complete unit. It has also been observed [1] 
that if the length of the cross-slipped segment increases, the edge segments of the loop can act independently, moving away from the pinning point and trailing two screw dislocations behind them; i.e., a non-regenerative dislocation source operates. A similar source mechanism has been observed to operate in NiAl [3].

Dislocations also multiply by the action of pole sources (Figure 4) [1]. The screw dislocation is pimed at point T. A highly mobile edge segment is nucleated on the dislocation line, which moves away rapidly generating two screw dislocations, one of which remains pinned, while the other moves slowly away from the source. The source is thus reset, and the pinned screw dislocation nucleates an edge segment moving in the opposite direction. The conditions to generate this type of pole source are not yet known, although it is worth mentioning that the tangle shown in Figure 1 also became a pole source at higher strains.

In samples with a low initial density of isolated dislocations $\left(<1 \times 10^{8} \mathrm{~cm}^{-2}\right)$, dislocation tangles form as mobile dislocations interact. As other dislocations impinge on the tangles they become pinned and bow out between the pinning points. The bowed segments contain edge dislocations that move rapidly away from the tangle, creating a mobile screw dislocation and leaving a dislocation in the tangle. Figure 5 shows an example of this increase in complexity with time. Although some dislocation tangles break up, in general the density and complexity of tangles increases with increasing strain.

These examples of dislocation generation, cross-slip, and dislocation interactions with obstacles and other dislocations illustrate the complexity of the problem facing the modeling community, if 
the simulations are eventually to be used to predict dislocation behavior and ultimately the stressstrain relationship of a material. The situation becomes more complicated if the deformation behavior in polycrystalline materials is to be simulated, as the interaction of dislocations with grain boundaries will need to be considered.

\section{Dislocation interactions with grain boundaries}

In general, grain boundaries act as barriers to dislocations, although under special circumstances (e.g., the line of intersection of the incoming and outgoing slip planes in the grain boundary plane are colinear and the line direction of the impinging screw dislocations is parallel to this line) the dislocations can pass unimpeded through the grain boundary. In most cases, the interaction with the grain boundary is more complex. Dislocations impinging on a grain boundary can enter the grain boundary where they can either retain their lattice Burgers vector [4], or dissociate to form perfect or partial grain boundary dislocations [5] or DSC dislocations [6]. The incorporated dislocations may be glissile or sessile in the grain boundary plane. The grain boundary can also eject dislocations into the neighboring grain (slip transfer) [7-11], although the site of the emitted dislocations need not be coincident with the entry point. Alternatively, a crack can nucleate and propagate along the grain boundary, leading to intergranular fracture [12-14]. The response of the grain boundary depends intimately on the orientation and chemistry of the grain boundary, and it can be altered by changing the boundary chemistry [15-17]. In Figure 6, we show one example [10] of slip transfer through a $\Sigma=3$ grain boundary in 310 stainless steel in which two slip systems, A and $\mathrm{B}$, impinged on the grain boundary. Dislocations were observed to emerge into the adjoining 
grain from different locations along the grain boundary; the primary cmerging system is labeled D and the secondary system $\mathrm{C}$.

To understand what controls the slip system activated by the grain boundary to allow slip transfer, three conditions were considered [10-11]: (a) the angle between the lines of intersection between the grain boundary and each slip system must be a minimum; (b) the magnitude of the Burgers vector of the dislocation left in the grain boundary must be a minimum; and (c) the resolved shear stress on the outgoing slip system must be a maximum. The result of applying these conditions to the situation shown in Figure 6 is given in Table 1. Slip system D is predicted if all three conditions are considered. The dislocations left in the grain boundary as a result of this emission process can slip in the grain boundary but their motion is impeded by the step in the grain boundary (marked by an arrow). Dislocations labeled $\mathrm{C}$ arise from the grain boundary emitting dislocations in response to the stress developed by the blocking of these grain boundary dislocations by the grain boundary step. These criteria have been applied to a number of grain boundary reactions in different materials and they have shown that, in general, a competition exists between criteria (b) and (c), and that it is these criteria that determine the outgoing slip system [11].

\section{DISCUSSION}

The experiments described above illustrate some observations made using the in-situ TEM deformation technique. The observations in Mo provide a clear picture of the processes of dislocation multiplication and work hardening in single-crystal Mo, and, by analogy, to many $\mathrm{BCC}$ materials in which cross-slip is possible and where there is a large differential between edge and 
screw mobility. These observations further indicate that understanding the physics of dislocation tangle structures is of primary importance in understanding the mechanical behavior of these materials. The slip transfer experiments made possible a model which not only accurately predicts the outgoing slip system, but which is independent of crystal structure, and is therefore likely applicable to many different materials.

\section{CONCLUSIONS}

The in-situ TEM deformation technique generates insights into the mechanical properties of materials, providing detailed information of dislocation dynamics, dislocation generation, and dislocation interactions with obstacles, other dislocations, and grain boundaries.

\section{ACKNOWLEDGEMENTS}

This work was funded by the Department of Energy under contract DEFG02-91-ER45349 and by Lawrence Livermore National Laboratory.

\section{REFERENCES}

1. M. Jouiad, B. W. Lagow, I. M. Robertson, and D. H. Lassila, in Multiscale Phenomena in Materials: Experiments and Modeling, D. H. Lassila, I. M. Robertson, R. Phillips, and B. Devincre, Eds. (MRS: Pittsburgh, 2000). 
2. F. Louchet and L. P. Kubin, Phys. Stat. Sol. A 56169 (1979).

3. D. Caillard, in High-Temperature Ordered Intermetallic Alloys VIII, E. P. George, M. Yamaguchi, M. J. Mills, Eds. (MRS: Pittsburgh, 2000), p. 737.

4. W. Bollman, B. Michaut, and G. Sainfort, Phys. Stat. Sol. A 13637 (1972).

5. R. C. Pond, Proc. Roy. Soc. A357 471 (1977).

6. W. Bollman, Crystal Defects and Crystalline Interfaces (Springer-Verlag: New York, 1970).

7. J. D. Livingston and B. Chalmers, Acta Metall. 5322 (1957).

8. Z. Shen, R. H. Wagoner, and W. A. T. Clark, Scripta Metall. 20921 (1986).

9. Z. Shen, R. H. Wagoner, and W. A. T. Clark, Acta Metall. 363231 (1988).

10. T. C. Lee, I. M. Robertson, and H. K. Birnbaum, Phil. Mag. A 62131 (1990).

11. W. A. T. Clark, R. H. Wagoner, Z. Y. Shen, T. C. Lee, I. M. Robertson, and H. K. Birnbaum, Scripta Metall. 26203 (1992).

12. G. M. Bond, I. M. Robertson, and H. K. Birnbaum, J. Mat. Res. 2436 (1987)

13. I. M. Robertson, G. M. Bond, T. C. Lee, D. S. Shih, and H. K. Birnbaum, J. de Physique 5 677 (1988)

14. T. C. Lee, I. M. Robertson, and H. K. Birnbaum, Acta Metall. 37407 (1989).

15. R. H. Jones in Mechanical Properties and Phase transitions in Engineering Materials: Earl R. Parker Symposium on Structure-Property Relationships, S. D. Antolovich, R. O. Ritchie, and W. W. Gerberich, Eds. (TMS: Warrendale PA, 1986), p. 227.

16. D. H. Lassila and H. K. Birnbaum, Acta Metall. 351815 (1987).

17. C. J. McMahon, Jr., Materials Characterization 26269 (1991). 
Figure captions:

1. Propagation of edge dislocations in Mo away from a tangle at low stress. As the edge dislocations move, they trail long screw segments behind them.

2. Cross-slip of screw dislocations in Mo. The positive (black) image represents the initial position and the superimposed negative (white) image represents the final position in each picture. The angle of the shift in direction is consistent with cross-slip between (110) and (112) type planes.

3. Dislocation interactions with obstacles.

4. Operation of a dislocation pole source in Mo.

5. Build-up of a complicated tangle in Mo by dislocation multiplication. The final image shows the same tangle after additional straining.

6. Slip transfer at a $\Sigma=3$ boundary in $310 \mathrm{SS}$. The pile-ups at A and B nucleate the dislocations at $\mathrm{D}$ and grain boundary dislocations; a pile-up in the grain boundary nucleates the dislocations at C [10].

Table 1: Parameters for prediction of slip transfer in the situation shown in Figure 6 [10]. 


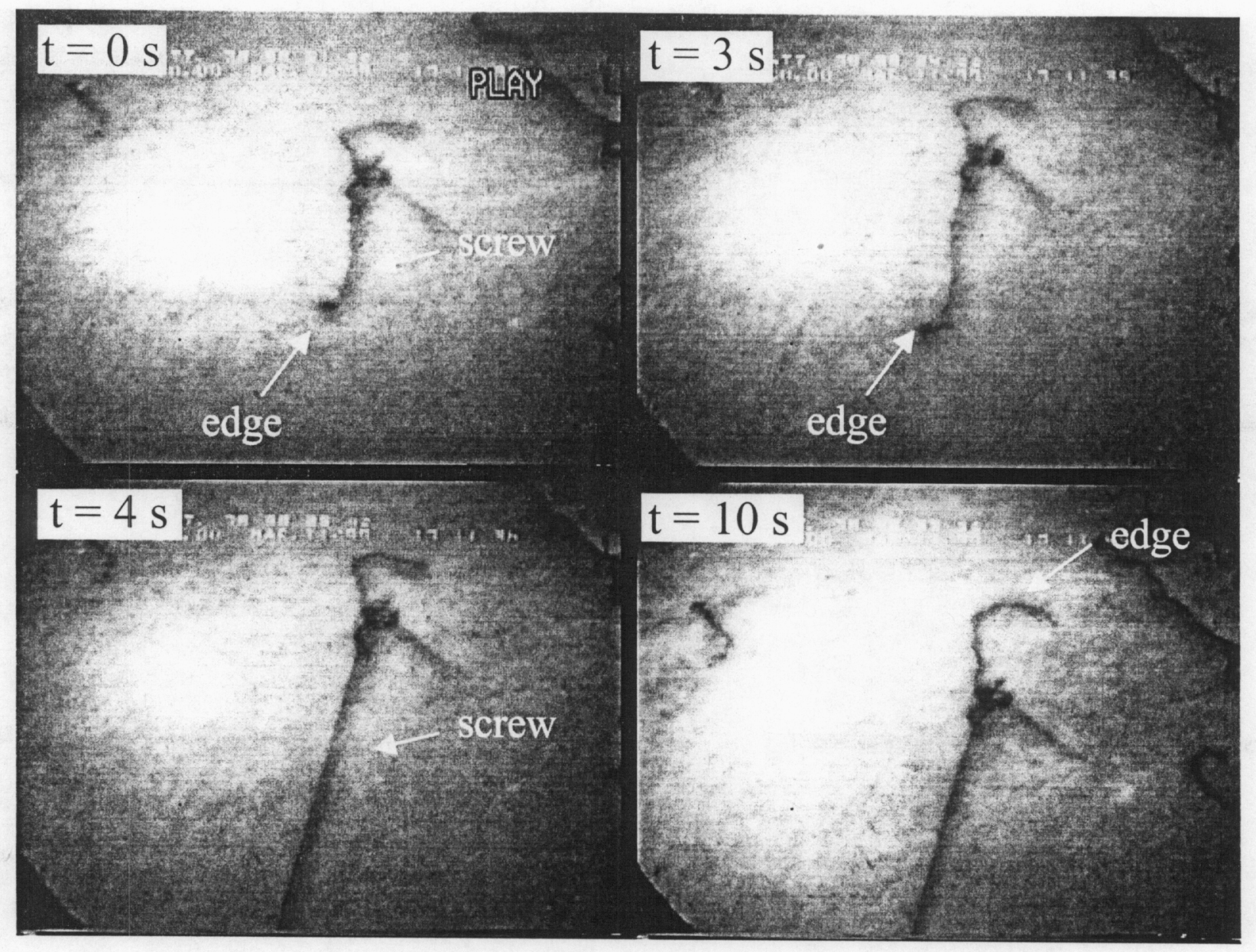

Lagow et al Figure 1 of 6 


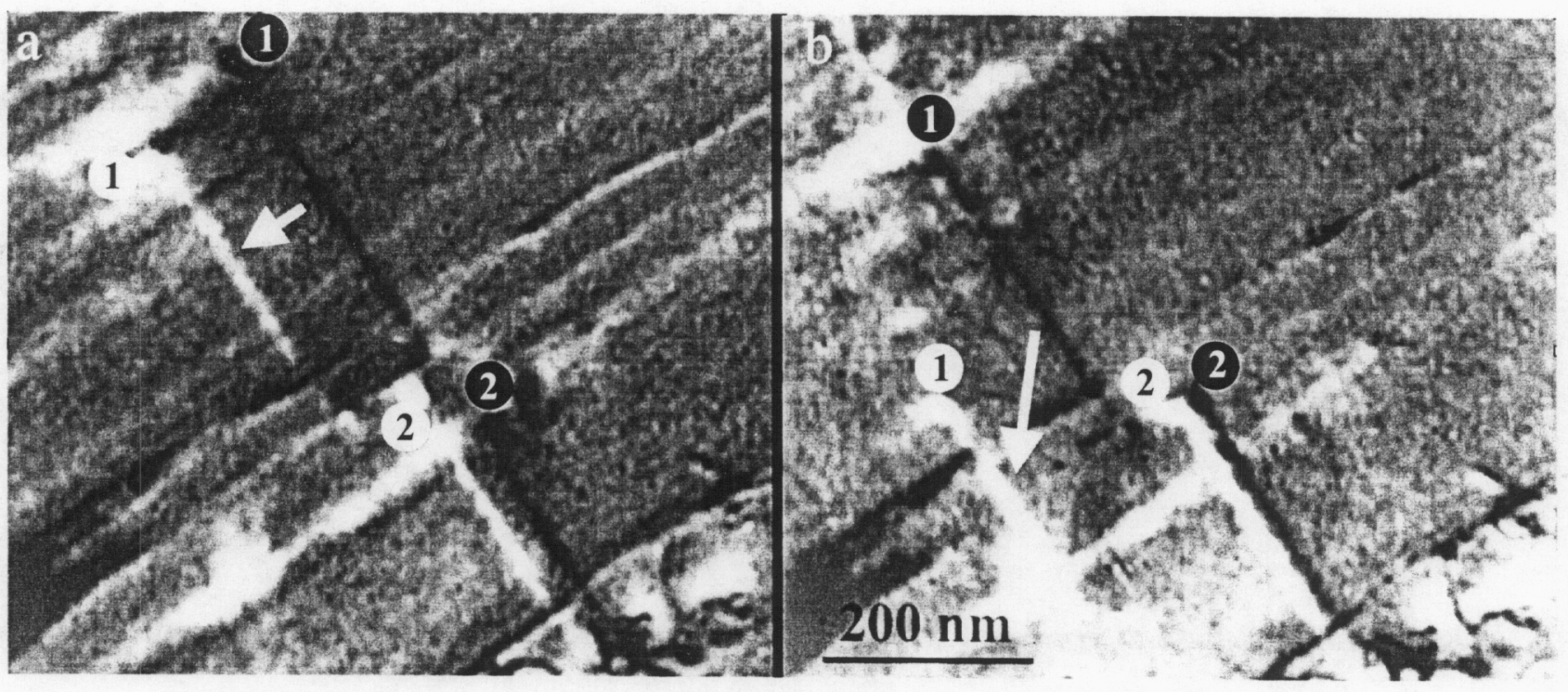

Lagow et al Figure 2 of 6 


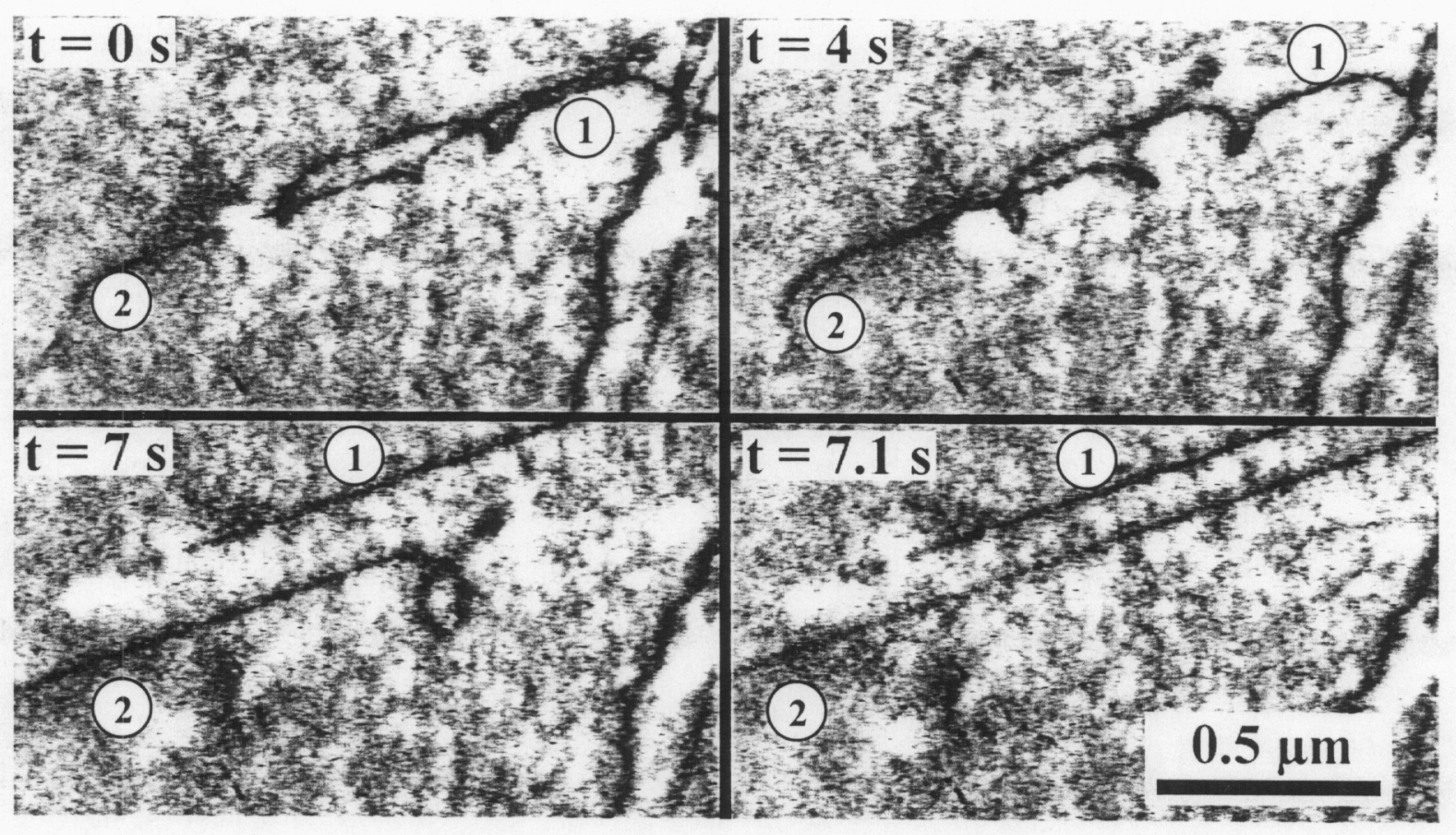

Lagow et al Figure 3 of 6 


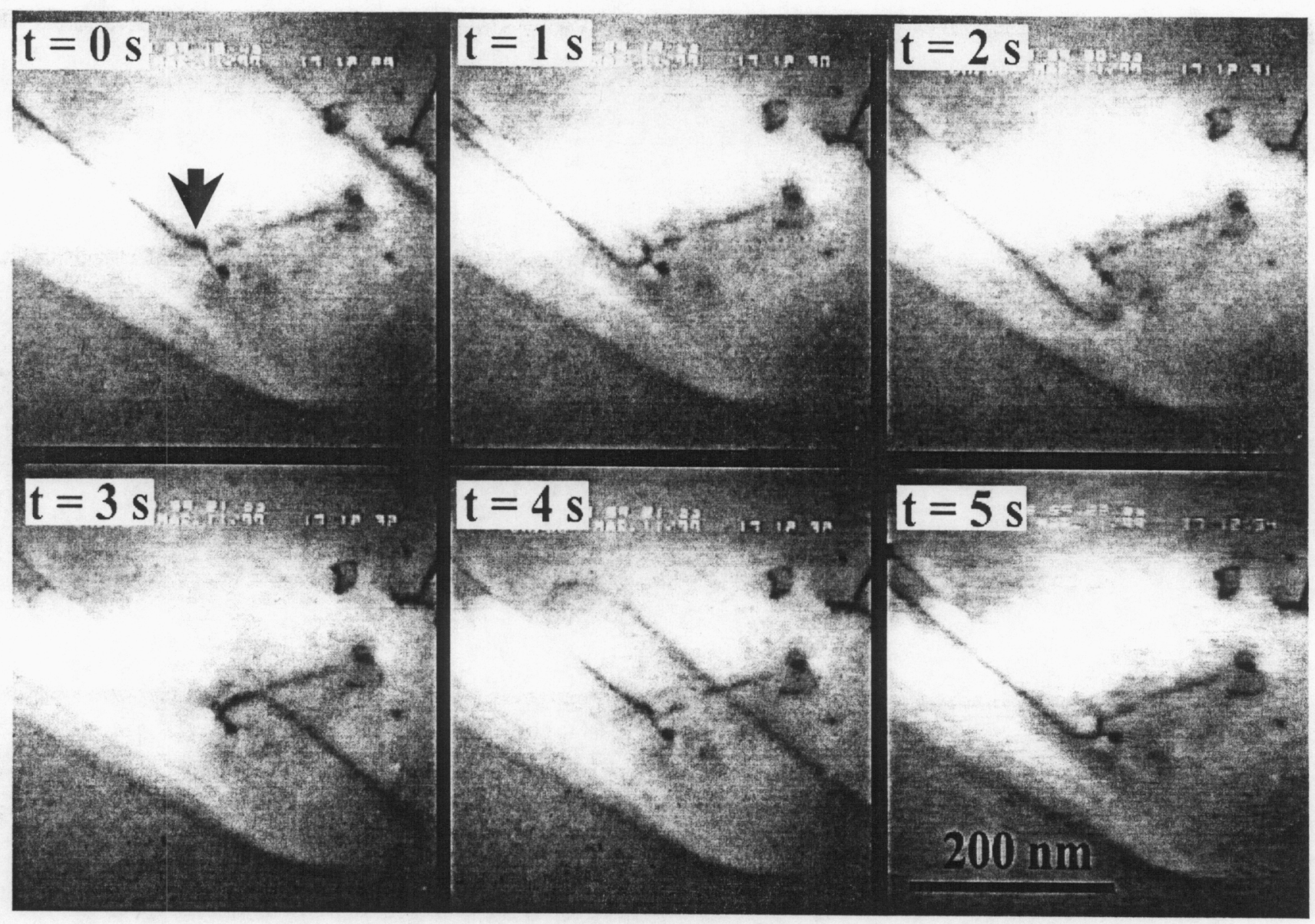

Lagow et al Figure 4 of 6 


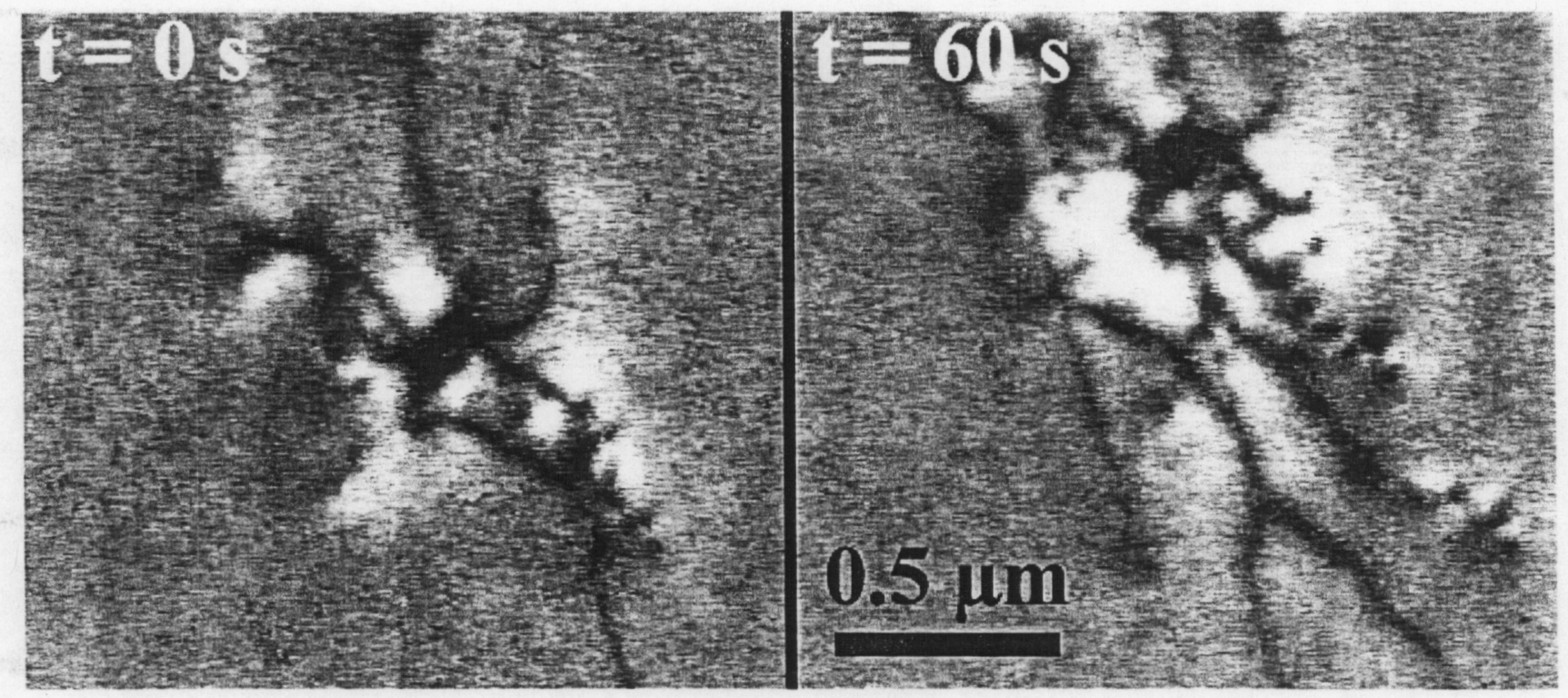

Lagow et al Figure 5 of 6 


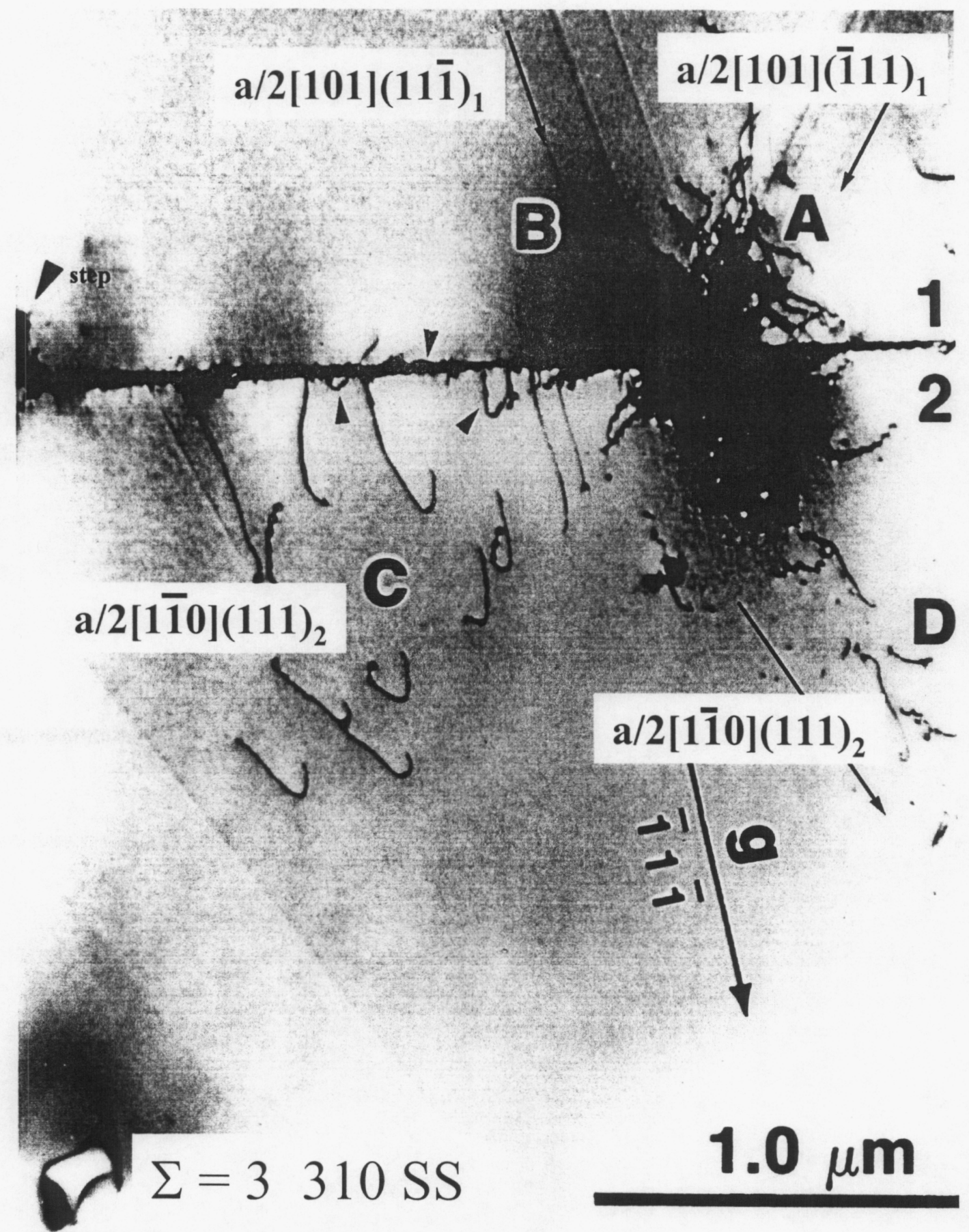




\begin{tabular}{|c|c|c|c|c|}
\hline Slip plane & Burgers vector & $\begin{array}{c}\text { Resolved shear } \\
\text { stress }\end{array}$ & $\begin{array}{c}\text { Intersecting } \\
\text { angle }\end{array}$ & $\begin{array}{c}\text { Burgers vector } \\
\text { of residual } \\
\text { grain } \\
\text { boundary } \\
\text { dislocation }\end{array}$ \\
\hline$(111)_{2}$ & $\frac{a}{2}[\overline{1} 10]_{2}$ & $\mathbf{0 . 9 0 1}$ & 0 & $-\mathbf{b}_{1}$ \\
\hline$(111)_{2}$ & $\frac{a}{2}[10 \overline{1}]_{2}$ & 0.139 & $\mathbf{0}$ & $\mathbf{b}_{3}-\mathbf{b}_{4}-2 \mathbf{b}_{2}$ \\
\hline$(111)_{2}$ & $\frac{a}{2}[01 \overline{1}]_{2}$ & 0.04 & 0 & $2 \mathbf{b}_{2}$ \\
\hline$(\overline{1} 11)_{2}$ & $\frac{a}{2}[110]_{2}$ & 0.68 & 60 & $-\mathbf{b}_{1}-\mathbf{b}_{4}-2 \mathbf{b}_{2}$ \\
\hline$(\overline{1} 11)_{2}$ & $\frac{a}{2}[\overline{1} 0 \overline{1}]_{2}$ & $\mathbf{0 . 9 2}$ & 60 & $\mathbf{b}_{3}$ \\
\hline$(\overline{1} 11)_{2}$ & $\frac{a}{2}[01 \overline{1}]_{2}$ & 0.57 & 60 & $2 \mathbf{b}_{2}$ \\
\hline$(1 \overline{1} 1)_{2}$ & $\frac{a}{2}[110]_{2}$ & 0.41 & 0 & $-\mathbf{b}_{1}-\mathbf{b}_{4}-2 \mathbf{b}_{2}$ \\
\hline$(1 \overline{1} 1)_{2}$ & $\frac{a}{2}[10 \overline{1}]_{2}$ & $\mathbf{0 . 8 4 2}$ & 0 & $\mathbf{b}_{3}-\mathbf{b}_{4}-2 \mathbf{b}_{2}$ \\
\hline$(1 \overline{1} 1)_{2}$ & $\frac{a}{2}[0 \overline{1} \overline{1}]_{2}$ & 0.52 & 0 & $-\mathbf{b}_{1}+2 \mathbf{b}_{3}$ \\
\hline$(11 \overline{1})_{2}$ & $\frac{a}{2}[\overline{1} 10]_{2}$ & 0.73 & 60 & $-\mathbf{b}_{1}$ \\
\hline$(11 \overline{1})_{2}$ & $\frac{a}{2}[\overline{1} 0 \overline{1}]_{2}$ & 0.19 & 60 & $\mathbf{b}_{3}$ \\
\hline$(11 \overline{1})_{2}$ & $\frac{a}{2}[0 \overline{1} \overline{1}]_{2}$ & 0.36 & 60 & $-\mathbf{b}_{1}+2 \mathbf{b}_{3}$ \\
\hline & & $\mathbf{b}_{1}=\frac{a}{6}[121]_{2}, \mathbf{b}_{2}=\frac{a}{6}[21 \overline{1}]_{2}, \mathbf{b}_{3}=\frac{a}{6}[\overline{1} 12]_{2}, \mathbf{b}_{4}=\frac{1}{3}[1 \overline{1} 1]_{2}$ & \\
\hline
\end{tabular}

Lagow et al. Table I 